\section{COMPLETE CARE TECHNOLOGY}

Waterpik Complete Care takes water flosser technology to the next level. Combining sonic brushing and water flossing, Waterpik Complete Care caters to all your patients' daily oral care needs in one convenient product.

The Sensonic Professional Plus is up to $29 \%$ more effective at removing plaque than other sonic toothbrushes, with a bristle speed that is 25\% faster. Combined with the Waterpik Water Flosser, which can remove up to $99.9 \%$ of plaque biofilm in treated areas in just 3 seconds, ${ }^{1,2}$ your patients will get a spectacular clean to keep their gingiva healthy between appointments.

Waterpik Complete Care can be used safely and effectively with implants, crowns, bridges, veneers and orthodontic appliances. With an advanced pressure control system, it is easy to use and requires less technique than traditional string flossing.
Waterpik Complete Care looks good too. With hygienic storage and a compact design, including a toothbrush travel case, it makes taking care of gingiva easy.

Introduce your patients to the premium oral care products from Waterpik International, Inc. - both they and their mouths will thank you!

For more information on Waterpik International, Inc. visit www. waterpik.co.uk.

1. Gorur A, Lyle, D M, Schaudinn C, Costerton J W. Biofilm removal with a dental water jet. Compend Contin Ed Dent 2009; 30 (Suppl 1): 1-6.

2. Cobb C M, Rodgers R L, Killoy W J. Ultrastructural examination of human periodontal pockets following the use of an oral irrigation device in vivo. J Periodontol 1998; 59: 155-163.

\section{NEW SHORT IMPLANTS HIT EUROPE}

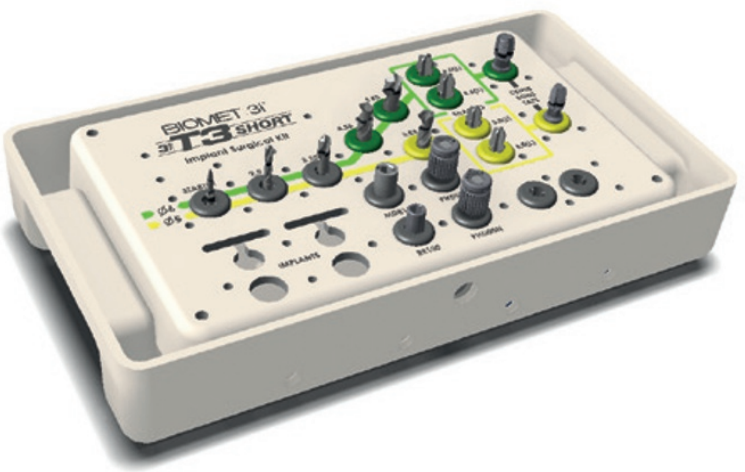

BIOMET 3i has now launched its new 3i T3 Short Implant in Europe. The new 3i T3 Short Implant is available in 5 and $6 \mathrm{~mm}$ lengths and 5 and $6 \mathrm{~mm}$ diameters. The new implant provides the following futures and benefits:

- The reduced length makes it an option for areas of minimal bone height without the need for vertical grafting procedures

- The blasted and acid-etched 3i T3 surface creates an average mean surface roughness of $1.4 \mu \mathrm{m}$ along the full length of the implant

- The dimensions of the surgical instrumentation and the $3 \mathrm{i}$ T3 Short Implant provide a tight implant-toosteotomy fit, to assist with primary stability ${ }^{2}$

- Manual platform switching is recommended for crestal bone preservation. ${ }^{3}$

In addition, BIOMET $3 \mathrm{i}$ is offering a new $3 \mathrm{i}$ T3 Short Implant compact surgical kit designed specifically to support site preparation and placement of 3i T3 Short Implants.

BIOMET $3 \mathrm{i}$ LLC is a leading manufacturer of dental implants, abutments and related products. Since its inception in 1987, BIOMET $3 \mathrm{i}$ has been on the fore- front in developing, manufacturing and distributing oral reconstructive products, including dental implant components and bone and tissue regenerative materials. The company also provides educational programmes and seminars for dental professionals around the world. BIOMET $3 \mathrm{i}$ is based in Palm Beach Gardens, Florida, with operations throughout North America, Latin America, Europe and Asia-Pacific.

For more information contact BIOMET 3i on 08006521233.

1. Gubbi P, Towse R. Quantitative and Qualitative Characterization of Various Dental Implant Surfaces. Poster

Presentation: European Association for Osseointegration, 20th Annual Meeting; October 2012; Copenhagen, Denmark. Online poster available at www.biomet3i. com/Pdf/Posters/Poster_421_EA0_Final.pd (accessed June 2015).

2. Meltzer A M. Primary stability and initial boneto-implant contact: The effects on immediate placement and restoration of dental implants. J Implant Recontr Dent 2009; I: 35-41.

3. Boitel N, Andreoni C, Grunder U, Naef R, Meyenberg K. A Three Year Prospective Multicenter, Randomized-Controlled Study Evaluating Platform-Switching for the Preservation of Peri-implant Bone Levels. Academy of Osseointegration, 26th Annual Meeting: 2011 March 3-5; Washington DC. Online poster available at: www.biomet3i. com/Resource\%20Center/Publications $\% 20$ of $\% 20$ Interest/Platform_Switching_for_ the_Preservation_of\%20Peri_Implant $\% 20$ Bone\%20Levels.pdf (accessed June 2015). A BIOMET 3i sponsored study.

Note: Dr Meltzer has a financial relationship with BIOMET 3i LLC resulting from speaking engagements, consulting engagements and other retained services. Dr Gubbi and Mr Towse contributed to the above research while employed by BIOMET $3 i$

\section{SAVE SPACE, SAVE TIME, SAVE MONEY}

Digital Dental's new Rextar X hand-held generator will change the way you take X-rays and relax your patients. Manufactured to the highest standards and CE certified, it is the latest in hand-held intraoral X-ray.

Save space - no awkward, bulky wall-mounted arm gives you more cupboard and storage space

Save time - you remain in the room so you take X-rays faster and reduce retakes. Patients feel more at ease because you stay chairside and their exposure is kept to a minimum. The dual shield design and a backscatter screen protecting the operator

Save money - similar in price to a high quality wall-mounted unit, but lightweight and portable, you can share it between surgeries or have an instant back-up for your existing X-ray units. Programmable for easy one-touch use with film, sensors or phosphor plates.

The latest in hand-held intraoral X-ray units, it is manufactured to the highest standards and is CE, ISO, TUV, FDA certified and RPA approved. The new design ensures higher image quality at a shorter exposure time and an ultra-low dose for the patient. So it's safer for the operator and the patient.

Visit www.digitaldental.co.uk or call 08007565642 to book a demonstration.

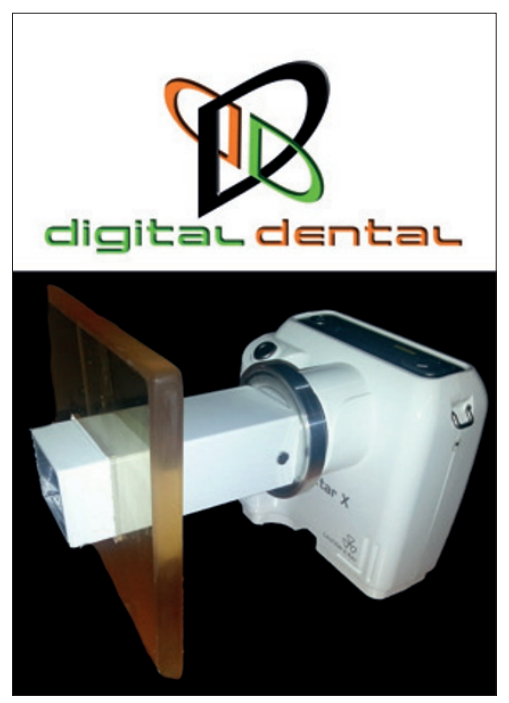

